\title{
Quartalsabrechnungen kann man unbegrenzt nachreichen
}

\begin{abstract}
- Nach einem Urteil des Sozialgerichts München vom 22. Januar 2016 sind Regelungen unzulässig, die die Abrechnung von ärztlichen Leistungen nach Ablauf einer Frist in Gänze ausschließen
\end{abstract}

(Az.: S 28 KA 212/13). Im konkreten Fall wurde eine Abrechnung von der zuständigen KV mit dem Argument verwehrt, dass ihre Abrechnungsbestimmungen eine Ausschlussfrist beinhalten. Demnach sei nach Ablauf von

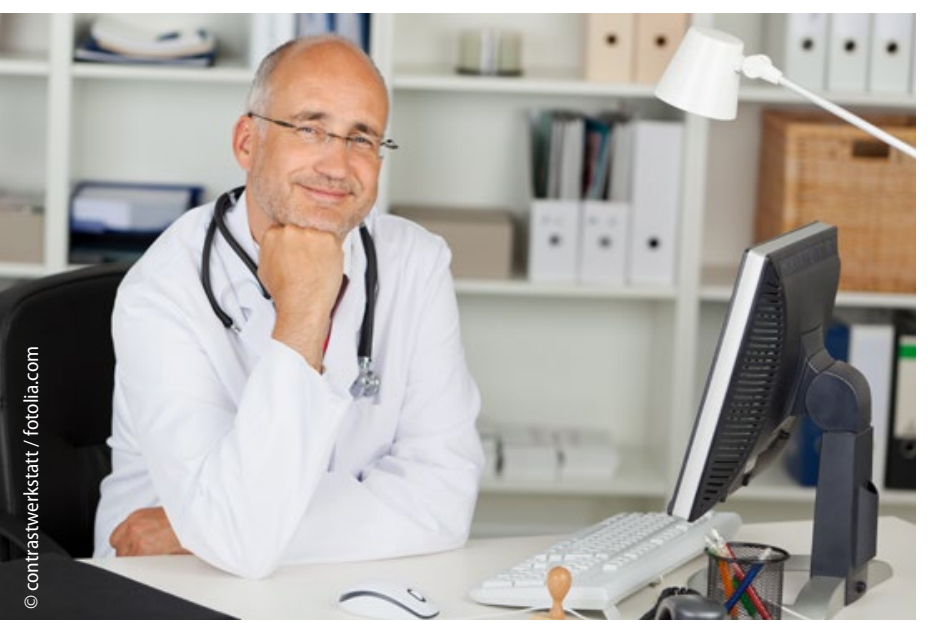

Abrechnung vergessen? Nur die Ruhe! neun Monaten ab dem Ende des Quartals eine nachträgliche Abrechnung von Leistungen komplett ausgeschlossen.

Das Sozialgericht gelangte jedoch unter Hinweis auf die Rechtsprechung des Bundessozialgerichts, konkret auf ein Urteil vom 22. Juni 2005 (Az.: B 6 KA 19/04 R), zu der Auffassung, dass ein vollständiger Ausschluss der nachträgli-

chen Abrechnung in diesem Fall unverhältnismäßig ist. Nach Auffassung der Richter muss zum einen berücksichtigt werden, dass das vollständige Fehlen von Abrechnungen als offensichtlicher Fehler für die KV hätte erkennbar sein müssen. Darüber hinaus ist das Sozialgericht der Auffassung, dass zwar Sanktionen für eine verspätete Abrechnung rechtmäßig sind, ein vollständiger Ausschluss einer nachträglichen Abrechnung aber als unverhältnismäßig anzusehen sei.

\section{MMW-KOMMENTAR}

Im vorliegenden Fall geht es um die Abrechnung ambulanter Notfälle. Zwar war es ein Krankenhaus, das auf die Nachvergütung von nachträglich abgerechneten Behandlungsfällen geklagt hat, das Urteil kann aber durchaus auf die vertragsärztliche Praxis übertragen werden.

\section{Folgerezept ausstellen - egal wo der Patient ist}

Ein Urteil des Landessozialgerichts Rheinland-Pfalz vom 3. März 2016 trägt zur Entbürokratisierung unserer Praxen zumindest in einem Punkt bei: Ohne konkrete Anhaltspunkte sind Vertragsärzte nach Auffassung der Richter bei laufender Behandlung nicht zur Nachfrage verpflichtet, ob sich ein Patient in stationärer Behandlung befindet (Az.: L 5 KA 140/14). Geklagt hatte eine Krankenkasse, die einen "sonstigen Schaden“ angemeldet hatte, weil ein Vertragsarzt Arzneimittel verordnet hatte, obwohl der Versicherte zu diesem Zeitpunkt im
Krankenhaus behandelt wurde. Weil er die Verordnung ohne Kontakt mit dem Patienten ausgestellt hatte, habe der Arzt seine Sorgfaltspflicht verletzt.

\section{MMW-KOMMENTAR}

Das Urteil ist wichtig, weil solche Fälle häufig vorkommen. Nach Auffassung der Kasse hätte der Arzt nämlich klären müssen, wo sich der Patient zum Zeitpunkt der Verordnung befunden habe, um die Notwendigkeit der Verordnung zu überprüfen. Das ist insbesondere bei einer Dauermedikation aber in der Regel überhaupt nicht möglich. Auch das
Landessozialgericht erkannte an, dass der Vertragsarzt gar nicht wusste, dass sein $\mathrm{Pa}$ tient gerade im Krankenhaus war. Darüber hinaus dürfe der Vertragsarzt nach $\S 15$ Abs. 2 des Bundesmantelvertrags (BMV- $\ddot{A})$ Arzneimittelverordnung auch dann ausstellen, wenn ihm der Zustand des Patienten aus der laufenden Behandlung bekannt sei. Ohne Anhaltspunkte dafür, dass die GKV gerade nicht leistungspflichtig sein könntewie eben im Falle einer Krankenhausbehandlung - hat der Vertragsarzt nach Auffassung auch keine Nachfragepflicht. Eine rechtliche Grundlage dafür gibt es nicht. 